\title{
Adaptive Measured Model for Cell Adhesive Force Using Dielectrophoresis Force
}

\author{
Cheng-Chang Lien \\ National Chiayi University \\ Department of Biomechatronic Engineering \\ Taiwan \\ Jie-Yu Cheng \\ National Chiayi University \\ Department of Biomechatronic Engineering
}

Taiwan

\author{
Chyung Ay* \\ National Chiayi University \\ Department of Biomechatronic Engineering \\ Taiwan \\ Chao-Wang Young \\ National Chiayi University \\ Department of Biomechatronic Engineering \\ Taiwan
}

\begin{abstract}
The Human Umbilical Vein Endothelial Cell Line (ECV304) was seeded on the polydimethylsiloxane(PDMS). The object of this study is to find out the adaptive measurement of cell adhesive force, which works in the optimal environment parameter, such as solution, working frequency, collagen smearing etc., to avoid the bubble formation in the solution. The result showed the cells seeded on the large area substrate with 2 $\mathrm{mm}$ structural spacing and the small area substrate with $100 \mu \mathrm{m}$ structural spacing have better adhesive force. It was also clear to find that large area substrates also showed faster cell growth and expansion. They are more suitable as culture substrates for the measurement of cell adhesion force. As for work solution, 2\% glucose solution that has relative low conductivity and concentration has the best measurement that effectively obtained cell adhesion force.
\end{abstract}

Keywords-Polydimethylsiloxane; Dielectrophoresis Force; Cell adhesive force

Endothelial cell;

\section{INTRODUCTION}

Many studies show that cells must attach and adhere to a substrate before they can start to spread on the substrate, proliferate, differentiate, and migrate. Therefore, the adhesion between cells and cells, or between cells and substrates, is an important aspect of cell-substrate behaviors.

Several studies have investigated the cell adhesion strength from mechanical point of view. In the past researches, cell adhesion strength has been studied as centrifugation force by centrifuge, tensile force by micropipette manipulation, shear force by parallel flow chamber and chemical binding force by atomic force microscope[1][2][3][4]. However, centrifugation force by centrifuge and shear force by parallel flow chamber can't work on a single cell and hence the measured strength of cell adhesion may not be accurate. Tensile force by micropipette manipulation and chemical binding force by atomic force microscope are both complicate and expensive techniques for the analysis of cell adhesion strength. DEP is the phenomenon in which a particle, such as a living cell, is polarized and moved by the electrical gravity in a non-uniform electric field[5]. Like gel electrophoresis, DEP can move neutral particles in a non-uniform AC electric field, for the separation and analysis of a variety of biological particles such as cells, DNA, and viruses[6][7][8]. In here, we utilized the DEP force acting on the cells to induce spatial movement for studying the cell adhesion strength. DEP may provide a new and cheap technique in cell adhesion measurement.

\section{MATERIALS AND METHODS}

\section{A. Dielectrophoresis Theory}

When an electrically neutral cell is placed in an electrical field, the cell can be polarized by the external force of the electrical field. DEP force is a phenomenon in which a force is exerted on a dielectric cell when it is subjected to a nonuniform electric field. The most commonly used electrode geometry to generate the non-uniform electric field. Cells will then move towards stronger or weaker regions of the electrical field. The movement of the cells depends on the cells properties, working solution, and the strength of the electrical field.

The dielectric constant $\varepsilon$ (fards/m) for the suspension solution of a living cell indicates the tendency of cell polarization when partial charges of the cell are subject to an electric field. Conductivity $\sigma(\mathrm{S} / \mathrm{m})$ can indicate the tendency for the free charges on the cell to move in an electric field, and usually depends on the solution ion content, dissociated ion concentration, charge amount and ion mobility. In this study, bioparticles are represented as cells. The average DEP force acting on a cell, which immersed in a medium and exposed to a spatially non-uniform can be described by [9]:

$$
\mathrm{F}_{\mathrm{DEP}}=2 \pi \varepsilon_{\mathrm{m}}\left[\frac{\varepsilon_{\mathrm{p}}-\varepsilon_{\mathrm{m}}}{\varepsilon_{\mathrm{p}}+2 \varepsilon_{\mathrm{m}}}+\frac{3\left(\varepsilon_{\mathrm{m}} \sigma_{\mathrm{p}}-\varepsilon_{\mathrm{p}} \sigma_{\mathrm{m}}\right)}{\tau\left(\sigma_{\mathrm{p}}+\sigma_{\mathrm{m}}\right)^{2}\left(1+\omega^{2} \tau^{2}\right)}\right] \mathrm{r}^{3} \nabla \mathrm{E}^{2}
$$

where in this study some constants be assumd: 
$\varepsilon 0$ : dielectric constant in vacuum, $8.854 \times 10-12$ (farads $/ \mathrm{m})$

(Ogata et al., 2001)

$\varepsilon \mathrm{m}:$ dielectric constant of solution (glucose), $76.5 \varepsilon 0$ (farads/m) (Mckee et al., 2000)

$\varepsilon p$ : dielectric constant of biological particle, $60 \quad \varepsilon 0$ (farads/m) (Morgan and Green, 2003), $3.53(\mu \mathrm{S} / \mathrm{cm})$

$\sigma \mathrm{m}$ : Electric conduction coefficient of solution (glucose)

$\sigma \mathrm{p}$ : Electric conduction coefficient of biological microparticle, $0.5(\mathrm{~S} / \mathrm{m})$ (Morgan and Green, 2003)

$\tau$ : characteristic time of dipole charge(sec) $\mathrm{r}$ : cell radius (m)

$\nabla E 2$ : gradient of electric field squared $(\mathrm{V} / \mathrm{m}) 2 \omega$ : electric field frequency $(\mathrm{rad} / \mathrm{sec})$

Hence, DEP force (FDEP) is can be calculated from the above equation. Since the DEP force is directed along the gradient of electric field intensity, $\nabla \mathrm{E} 2$, and electric field intensity (E) is proportional to the electric potential (V) which works in the electric field when the length of medium between two electrodes is constant.

\section{B. Materials}

The human endothelial cells, ECV304 was obtained from America Type Culture Collection (ATCC). SYLGARD ${ }^{\circledR} 184$ silicone elastomer kit was purchased from Dow Corning (Taipei, Taiwan). All culture materials were purchased from Gibco (Grand Island, NY, USA) and all chemicals of reagent grade were obtained from Sigma (St Louis, MO).

\section{The Measurement of Cell Adhesion Force}

The experiment utilized micro-processing technology to etch a glass plate with two different width electrodes to produce non-uniform electric field (Fig. 1a). For DEP force generation, electrical potential was supplied to the aluminum electrode (Fig. 1b) by a function generator and a power amplifier to produce an uneven electrical field. The scheme of dielectrophoresis (DEP) force measurement system is shown in Fig. 2. For measurement of cell adhesion strength, cells were first seeded on collagen type 1 and fibronectin coated PDMS membranes respectively. At certain time intervals after cell seeding, the PDMS membranes were covered with two different width electrodes plate (deposition aluminum with a height of $800 \mathrm{~nm}$; the shorted distance between electrodes set at $80 \mu \mathrm{m}$, with the greatest distance between electrodes at $100 \mu \mathrm{m})$ to produce DEP force with the supply of electrical charge (Fig. 1b). During the measurement of cell adhesion strength, electrical potential was increased in the rate of one-third voltage per second from 0 to $10 \mathrm{~V}$ and then changed to onetenth voltage per second until the focal cell was detached from the PDMS surface. Till cell detached from the PDMS surface, the electrical potential $(\mathrm{V})$ is recorded to be the strength of cell adhesion.

\section{Methodology - Optimal Measurement Experiments}

The object of this study is to find out the adaptive measurement of cell adhesive force, which works in the optimal environment parameter, such as solution, working frequency, collagen smearing etc., to avoid the bubble formation in the solution. It is to use collagen smearing to culture endothelial cells on different PDMS micro-structure substrate, investigate the experimental factors to affect cell adhesion, optimal smearing method, possible issues and solutions to obtain the desired cell growth condition.

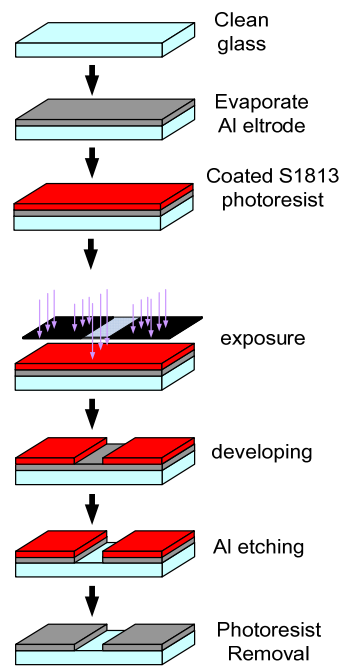

(a)

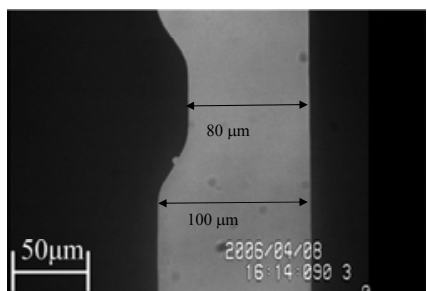

(b)

FIGURE I. MICRO-ELECTRODE PROCESS AND PRODUCT

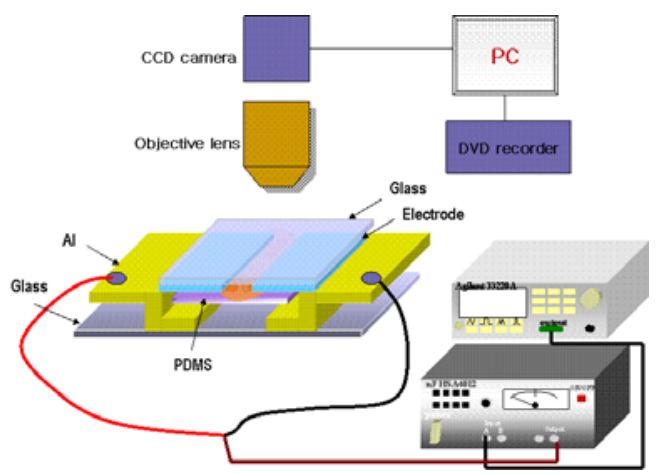

FIGURE II. SYSTEM DIAGRAM

Since the cell seeded on the substrate in the research was polydimethylsiloxane (PDMS) which hydrophobicity prevented collagen smearing, microstructure was built on PDMS to hold the solution in the cell culture area by capillary effect. Investigation was also made between micro-structured and non-structured PDMS and for different structural spacing. Through this, whether structure could affect adhesion significantly would be known, as well as whether different structural spacing when cells have different growth space would generate different physiological mechanism. 


\section{E. D-1 Selection of Work Solution}

Dielectric property, conductivity and dissociation degree for different work solutions would change the effect of DEP force on cell behavior. Overly high osmolarity can cause leakage of water inside cell membrane and crenation; overly low osmolarity can cause water from work solution to enter cell membrane and expand, or even rupture, the cell. Thus, selection of solution and concentration is an essential parameter in the experiment.

\section{F. D-2 Style of Cell Culture Substrate}

The research used collagen smear on different PDMS micro-structure substrates for cell adhesion. Since PDMS is hydrophobic, when collagen is smeared on PDMS, its contact angle with PDMS is large due to surface tension and beads are formed. So it is necessary to have an integrated smearing process to provide each cell with identical growth condition. In this study, there are two ways to find out which style is better to cell culture. One way is compared no-modified and modified the surface property of substrate through oxygen plasma process. The others is changed the structure of substrate. It is hoped to reduce the usage of collagen and overcome hydrophobicity.

The specifications for the three substrates are as follows:

1. Flat substrate: flat PDMS substrate without any column structure and culture cells on it.

2. Large substrate: PDMS with an array of four columns (diameter $100 \mu \mathrm{m}$ ); culture cells on the cross flat area among the four columns; the width for flat area is $2 \mathrm{~mm}$.

3. Small substrate: PDMS with three columns (diameter $100 \mu \mathrm{m}$ ); column spacing is $100 \mu \mathrm{m}$; culture cells on the blank area between columns.

\section{RESULTS AND DisCUSSION}

\section{A. Selection of Work Solution to Avoid Bubble Formation}

The research used $\mathrm{NaCl}$ and glucose solution as the primary work solution. It was found in the beginning of cell seeding, the adhesion was small, so it was easy for DEP force to detach from the substrate, once the cell adhesion became large, the applied voltage increases, but the tendency of electrolysis for aqueous solution also increased, and bubbles were formed on electrode surface and cell squeezing also occurred. Formation of bubbles affected measurement of cell adhesion. Besides, formation of bubbles also tended to damage the electrodes. Different solvent characteristic would have different concentration in water, so ion content and dissociation also vary, and there is different conductivity. The relationship between work voltage and solution to bubble formation is showed in Table 1. For each concentration, five experiments were conducted and voltage at each bubble formation was recorded into table for comparison.

From Table 1, it was found that when glucose solution was used as work solution for adhesion force measurement, with consideration that extremely low osmolarity would have impact to cell physiology or cell membrane rupture, it was suggested
$2.0 \%$ glucose solution was the optimal work solution to assess human endothelial cell adhesion by DEP force.

\section{B. Style of Cell Culture Substrate}

From Fig. 3 it was found that after surface modification by oxygen plasma treatment then contact angle changed a lot and the original hydrophobic nature was changed to hydrophilic. Therefore, after oxygen plasma treatment, experiment should proceed immediately to minimize errors due to surface property variation.

The experiment used $2.0 \%$ glucose solution as work solution with work frequency of $1 \mathrm{MHz}$, and used flat PDMS substrate treated by no treatment and oxygen plasma treatment, and then seeded cells for $0 \sim 7$ hours prior conducting adhesion measurement.

TABLE I. WORK VOLTAGE OF BUBbLE FORMATION UNDER DifFERENT WORK SOLUTION AND CONCENTRATION

\begin{tabular}{|c|c|c|c|c|c|c|c|}
\hline $\begin{array}{c}\text { solutio } \\
\text { n }\end{array}$ & $\begin{array}{c}\text { Concen } \\
- \\
\text { Tratio } \\
\mathbf{n} \\
(\%)\end{array}$ & $\# 1$ & \#2 & $\# 3$ & \#4 & $\# 5$ & $\begin{array}{c}\text { Voltage } \\
*(\mathrm{~V})\end{array}$ \\
\hline $\mathrm{NaCl}$ & 0.4 & 12.0 & 10.7 & 12.0 & 12.0 & 10.7 & 11.4 \\
\hline $\mathrm{NaCl}$ & 0.9 & 8.2 & 8.2 & 8.2 & 8.2 & 8.2 & 8.2 \\
\hline $\mathrm{NaCl}$ & 1.5 & 7.0 & 5.7 & 7.0 & 8.2 & 7.0 & 6.9 \\
\hline $\mathrm{NaCl}$ & 2.0 & 10.7 & 10.7 & 10.7 & 9.4 & 10.7 & 10.4 \\
\hline $\mathrm{NaCl}$ & 3.0 & 7.0 & 8.2 & 8.2 & 8.2 & 8.2 & 7.9 \\
\hline $\begin{array}{c}\text { glucos } \\
\mathrm{e}\end{array}$ & 0.3 & 27.7 & 29.0 & 27.7 & 27.7 & 27.7 & 27.9 \\
\hline $\begin{array}{c}\text { glucos } \\
\mathrm{e}\end{array}$ & 2.0 & 21.1 & 14.6 & 29.0 & 29.9 & 29.9 & 24.9 \\
\hline $\begin{array}{c}\text { glucos } \\
\mathrm{e}\end{array}$ & 5.0 & 22.4 & 15.9 & 22.4 & 22.4 & 21.8 & 20.9 \\
\hline $\begin{array}{c}\text { glucos } \\
\mathrm{e}\end{array}$ & 7.0 & 25.0 & 19.8 & 15.9 & 13.3 & 15.9 & 17.9 \\
\hline $\begin{array}{c}\text { glucos } \\
\mathrm{e}\end{array}$ & 9.0 & 15.9 & 15.9 & 15.9 & 14.6 & 15.9 & 7.9 \\
\hline
\end{tabular}

$*(\mathrm{~V})$ : Average working voltage at bubble formation

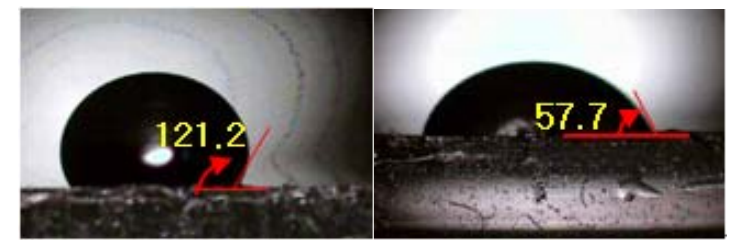

(a) Before treatment

(b) after treatment

FIGURE III. CONTACT ANGLE BEFORE AND AFTER OXYGEN PLASMA TREATMENT

Fig. 4 was adhesion diagram for flat substrate and indicated several parts that had abrupt drop of adhesion force. Since the culture dish and growth environment were identical and adhesion force was measured, theoretically adhesion force would increase with seeded time and start leveling off after several hours. But the unusual phenomenon found in the curve suggested hydrophobic PDMS made it difficult for collagen evenly smeared, and under-smeared area could have significant decrease in adhesion force. It was possibly because after PDMS substrate surface changed from hydrophobic to hydrophilic, although solution was easier to smear on the surface, the 
limited usage of collagen and no surface structure to hold the solution caused poor overall uniformity of smearing.

\section{Cell Adhesion Force for Different Microstructures}

To test collagen smearing state, besides the original flat substrate, there were another two different PDMS microstructures. There were flat substrate, large area substrate and small area substrate.

From Fig. 5 it was found that the cell adhesive force in the experiment with three different substrate microstructures when cells were seeded on large area substrate and small area substrate. When further comparison was made to the abrupt drop of adhesion force, it was also found that there was a trend that adhesion force increased with seeded time. It can be found that when collagen was smeared on microstructure, capillary force between columns would keep the solution in the gap. Therefore, besides adhesion curve could prove that structured PDMS had better adhesion. When the cells were seeded on large area substrate or small area substrate, it was clear that their adhesion force increased with seeded time.

From Figure 5 it was found that among the three substrates the adhesion force was mostly lower in the flat substrate, and its maximum adhesion force occurred at 2.5 hours and the adhesive force was about $7.2 \mathrm{nN}$. Further, with increasing seeded time, the adhesion force did not increase. When cells were seeded on large substrate and small substrate, the maximum adhesion force occurred at 7 and 6.5 hours and adhesion force was 21.6 and $15.4 \mathrm{nN}$. The large substrate had larger adhesion force than the smaller substrate.

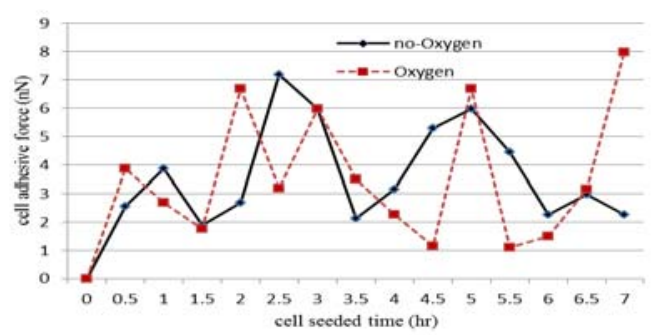

FIGURE IV. CELL ADHESION FORCE ON FLAT PDMS SUBSTRATE

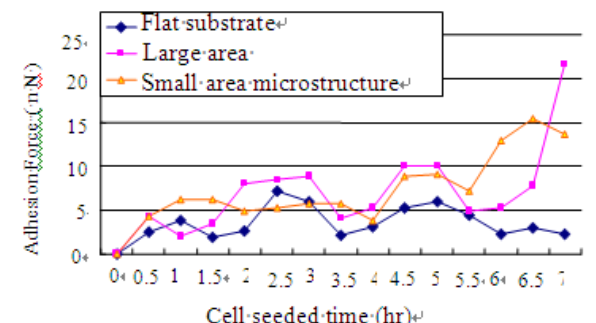

FIGURE V. CELL ADHESION FORCE FOR DIFFERENT SUBSTRATES

\section{CONCLUSIONS}

The research is mainly to use DEP force to measure cell adhesion force and establish the optimal measurement model. The conclusions are summarized in the following:

1. When $\mathrm{NaCl}$ is used as work solution and the concentration is around $0.4 \% \sim 3 \%$, it is easy to form bubbles and affect adhesion measurement. If weak electrolyte, $2.0 \%$ glucose solution, is used as work solution, adhesion measurement can be conducted smoothly.

2. For oxygen plasma treatment on flat PDMS substrate, both experiment results and literatures indicated surface hydrophobicity was clearly improved. Compared to nontreated PDMS flat substrate, the treated one has better adhesion force.

3. When the endothelial cells are cultured on structured large PDMS substrate and small substrate, the maximum adhesion occurs at 7 and 6.5 hours and the forces are 21.6 and $15.4 \mathrm{nN}$, compared to $0 \mathrm{nN}$ before adhesion. The large substrate had larger average adhesion force than the small substrate. This means the large area substrate has better adhesion effect.

4. When the large area substrate with column spacing 2 $\mathrm{mm}$ is used to culture endothelial cells, it facilitates cell adhesion speed to obtain better growth condition. It is more suitable as the cell culture substrate for adhesion measurement.

\section{REFERENCES}

[1] O. Thoumine, A. Ott, D. Louvard, "Critical centrifugal forces induce adhesion rupture or structural reorganization in cultured cells." Cell Motil Cytoskeleton. Vol. 33, pp. 276-287, 1996.

[2] O. Thoumine, A. Ott, "Comparison of the mechanical properties of normal and transformed fibroblasts.” Biorheology. Vol.34, pp.309-326, 1997.

[3] G. A. Truskey, T. L.Proulx, "Relationship between 3 T3 cell spreading and the strength of adhesion on glass and silane surfaces." Biomaterials. Vol.14, pp.243-254, 1993.

[4] Z. Leonenko, E. Finot, M. Amrein, "Adhesive interaction measured between AFM probe and lung epithelial type II cells." Ultramicroscopy, vol. 107, pp. 948-953, 2007.

[5] T. B. Jones, Electromechanics of particles. Cambridge, Cambridge University Press; 1995.

[6] R. Pethig, "Dielectrophoresis: using inhomogeneous AC electric fields separate and manipulate cells." Crit. Rev. Biotechnology, vol.16, pp.331-348, 1996.

[7] H .Dalir, Y. Yanagida, T. Hatsuzawa, "Probing DNA mechanical characteristics by dielectrophoresis", Sensors and Actuators B. vol.136, pp.472-478, 2009.

[8] H. Morgan, M. P. Hughes, N. G. Green, "Separation of Submicron Bioparticles by Dielectrophoresis", Biophysical Journal.vol. 77, pp. 516$525,1999$.

[9] L. Benguigui, I. J. Lin, "More about the dielectrophoretic force", J. Appl Phys. Vol. 53, pp.1141-1143, 1982. 